\title{
Crossing the Demarcations: How Tourism Reinforced the Wife-Prostitute Hierarchy in Tokugawa Japan
}

\author{
Yunran Wang ${ }^{1}$ \\ ${ }^{I}$ Guangzhou Zhixin High School, Guangzhou, Guangdong 510080, China, michellewang2003@outlook.com
}

\begin{abstract}
In the 18th century, prosperous commercial development and national infrastructure projects contributed to an unprecedented travel boom in Japan [1]. As demonstrated by previous research, since travel nurtured an inclusive environment in which people of all social ranks were meeting each other, it helped loosen the status system established by the shogunate. Nonetheless, travel also took a negative yet often neglected role in reinforcing the female hierarchy that divided virtuous "wives" and promiscuous "prostitutes." This paper will argue that, as a form of social activity that allowed men and women alike to cross many social parameters and to therefore recreate their perception of the world, travel successfully reinforced the wife-prostitute hierarchy, or dichotomy, in Tokugawa Japan, which can also be seen as an embodiment of Sigmund Freud's Madonna-whore complex theory. The paper will start by introducing the origins of this hierarchy and will then employ published works of the $18^{\text {th }}$ century to discuss how tourism encouraged men to embrace the concept. It will then use ukiyo-e paintings and women's travel diaries to analyse how voyaging on the road helped elite women accept the female hierarchy and finally put themselves into the higher rank by taking a condescending standpoint.
\end{abstract}

Keywords: Edo travel boom, women's status, Madonna-whore complex (wife-prostitute dichotomy), travel diaries

\section{INTRODUCTION: THE EMERGENCE OF THE FEMALE HIERARCHY}

In the $17^{\text {th }}$ century, Ieyasu Tokugawa ended the years of the Warring States. What ensued were the growing commerce, industries, and agriculture. The higher standard of living enabled by this prosperity and the peaceful environment of the Tokugawa period, in addition to the road improvement projects prompted by the need to form a national market, gave rise to the Edo travel boom. On the road were men and women from all walks of life - daimyos heading for alternate attendance, commoners going to Ise for pilgrimage, and wives going to their natal homes [2]. However, at the time the free and flexible tourism started to develop, a female hierarchy was already taking roots in the Tokugawa society.

Although, as will be shown later, men became the primary beneficiaries of the hierarchy, the dichotomy initially emerged as a byproduct of the Tokugawa shogunate's attempt to regulate sex trade and to extend protections to women [3]. After the violent era of the Warring States, Ieyasu Tokugawa was determined to create a long-lasting peace in Japan. To that end, the bakufu implemented the samurai-peasant-artisanmerchant status system to divide its subjects into different status groups [2], as a way to facilitate each group's fulfillment of obligations and to prevent people from joining efforts together to override the shogunate [1] Also included in this plan to restore peace and order was the regulation of the sex trade. The bakufu passed laws to prohibit wives from being indentured into prostitution [3] and also made efforts to confine prostitution to urban pleasure quarters [4], such as the famous Yoshiwara in Edo. As Amy Stanley wrote, the bakufu laws and the walls that separated the pleasure quarters from the outside world were "inviting" men to divide women into two categories: the wives and the prostitutes [4]. The word "wives" here does not refer to the married women only, but is a reference to the group of elite women, including the wives and daughters, who were required by Confucian moral texts to be virtuous "virgins." In contrast, those confined inside the pleasure quarters were courtesans that embodied men's erotic nature. Since courtesans were usually forced into prostitution because of poverty [3] and the virtuous elite women usually came from well-to-do families, this female hierarchy was in fact built upon the samurai-peasant-artisan-merchant hierarchy consisting of 
the upper-class elites and the lower-class commoners. In short, the bakufu's attempt to preserve peace resulted in the emerging female hierarchy made up of the higherrank elite women and the lower-rank poor prostitutes.

\section{INDULGING IN PROSTITUTION ON THE ROAD: HOW TOURISM ENCOURAGED MEN TO EMBRACE THE FEMALE HIERARCHY}

Although the bakufu regulations indirectly gave rise to the female hierarchy, neither men nor women immediately came to accept it as a social norm. In particular, prostitutes were strictly confined in urban pleasure quarters and were not prevalent enough to be perceived as a specific category of women. However, as men started their journeys around Japan, the demand for prostitutes in the countryside dramatically increased. Although the bakufu was somewhat reluctant to sanction the expansion of prostitution to the countryside out of concerns for social order, it finally agreed to allow two serving girls (prostitutes) in each inn to encourage post stations' economic development [4]. Under the loosened regulations, brothels in post stations along the Five Highways sprang up exuberantly. These brothels on the road thus gave male travelers opportunities to meet with lower-class prostitutes and gave some commoner men the first chance in their life to indulge in prostitution. While these brothels on the road laid the ground for the popularization of prostitutes and the establishment of the female hierarchy, the print culture of the time followed to reinforce the trend.

\subsection{Prostitutes as a Connection with Locals}

According to Laura Nenzi, one of the reasons why brothels became a nearly necessary tourist activity in the Tokugawa period lies in the ability sex has in connecting travelers with the locals, therefore alleviating male travelers' sense of loneliness and alienation in places unfamiliar to them [5]. As more and more male travelers went to visit brothels, prostitution became normalized, not only at the post stations, but everywhere. It could also be said that, at the time travel helped create Japanese people's national identity, it also allowed Japanese men to form a shared interest in prostitutes. This male demand made serving girls a necessity in post stations. As the headman at the Tokaido's Kawasaki station said in 1721, "there are stations that have these women [serving girls] and those that do not. Those with women prosper, while those without decline" [7]. In addition, seeing other men flirting with prostitutes at brothels could also give men a confirmation that prostitution was validated. Consequently, at the time most men subordinated their wives and daughters according to Kaibara Ekiken's guidelines of "chastity," "obedience," and "tenderness," [6] men themselves came to embrace extramarital sex in brothels, successfully employing the dichotomy between wives and prostitutes.

\subsection{The Erotic Print Culture}

As traveling experience itself encouraged men to embrace the two categories of women, published works of the time helped further normalize prostitution and even played a role in stigmatizing prostitutes. The $17^{\text {th }}$ and $18^{\text {th }}$ century witnessed a print culture boom, which encouraged writers and painters to intentionally create works that could flatter public readers [7]. As more and more men became fascinated by brothels along the travel routes, these commercial authors even started to publish travel guides to brothels on the Five Highways [5]. For example, Koikawa Shozan's Travel Pillow for the FiftyThree Stations features one shunga for each station, depicting travelers copulating with local girls [8]. Besides, some novels featured travelers' erotic experiences. For instance, on their way to the Ise Shrine, the main characters Kita and Yaji in Ikku Jippensha's novel Shank's Mare show a predatory attitude towards women they encounter and freely flirt with serving girls at inns [9]. As a bestseller at the time, the book must also have reinforced prostitutes' image as promiscuous women that could be manipulated by men however they wanted, which stood in stark contrast to the "virgin" persona these men designated to their wives and daughters.

What's more, intended to exaggerate and reinvent the reality so as to attract readers' attention, popular fictions and woodblock prints at the time tended to emphasize prostitutes' seductive and depraved image, despite the fact that most courtesans were forced into prostitution due to poverty [6]. For example, one ukiyo-e (woodblock print) in Ando Hiroshige's Fifty-Three Stations of the Tokaido series depicts some serving girls dragging travelers into a teahouse at the Goyu [10]. Also, Ihara Saikaku's novel The Life of an Amorous Woman describes how a woman born into a noble family led the life of a corrupted courtesan because of her erotic nature [11]. These misleading popular works unconsciously reinforced the popularization of prostitutes and even gave rise to their stigmatized image, helping to validate men's act of embracing prostitution and taking advantage of the female hierarchy.

\section{BECOMING ACCOMPLICES ON THE ROAD: HOW TOURISM GAVE ELITE WOMEN OPPORTUNITIES TO EMBRACE THE FEMALE HIERARCHY}

At the time tourism and related works encouraged men to embrace the two ranks of women and thus to reinforce the female hierarchy, women themselves played a particularly important role in consolidating the dichotomy. Both wives and prostitutes might be to blame. 
However, as mentioned before, since most prostitutes in the Tokugawa period were indentured into prostitution because of poverty [4], they usually had no choice but to passively receive this lower-class niche. It was thus the elite women who took a more solid role in consolidating the internal division amongst women. This part of the paper will therefore discuss how tourism gave elite women opportunities to realize and accept the female hierarchy. This transformation on elite women's part can be divided into two stages: the consolidation of the Tokugawa status system in elite women's mind and elite women's familiarization with the "virgin" persona, which could be seen from their contempt for the poor commoners, prostitutes in particular.

\subsection{Status Markers and Status Awareness on the Road}

Since the female hierarchy consisting of elite women and poor prostitutes was built upon the Tokugawa samurai-merchant status system, it is important to first understand how tourism helped elite women reaffirm their upper-class identity in the broader social hierarchy. Before embarking on their journeys, most elite women acted as stay-at-home wives or daughters. Even though they enjoyed the status of aristocrats or samurais, they might not find their status a privilege as the most important rule for them in the domestic environment was being subordinate to the male head of the household (ie), which could have obscured their awareness of elite status. Travel, on the other hand, provided elite women with a diverse environment in which they would meet with people of all social status, which naturally pushed them to compare themselves with others. Comparison highlighted the status differences and thus made elite wives more aware of their elite identity.

Status markers on the road can be the most evident visual symbols that attracted elite women's attention. These status symbols - such as the style of kimono, women's hairstyle, the type of vehicle one traveled in [5] - in turn cultivated elite women's acceptance of their social status, albeit sometimes with reluctance. Since the one of the greatest necessity on one's journeys must be the travelling vehicle, I will use it as an example to illustrate how status markers could have reinforced elite women's status awareness.

In most cases, elite women would travel in palanquins. For example, when the Sakai Magistrate wife Tsuchiya Ayako embarked on the trip to her husband's new post in 1806 [5], she recorded in her diary that she "was pushed into the dark palanquin" while her attendants were preparing to walk along her palanquin in procession [5]. As can be observed from the passive tense "was pushed" and the word "dark," Ayako was somewhat reluctant to travel in such a confined vehicle. Sitting in the miniature cubicle, she felt oppressed: "I could even not tell where we were," [5] wrote Ayako. Laura Nenzi thus interprets the palanquin as a reduced-scale room that resembled the domestic, confined environment experienced by elite wives every day [5]. Nonetheless, struggling with all these restrictions, Ayako finally wrote, "Thinking this is the law of us women, I did not say a word" [5]. This compliance shows that the palanquin was not only a resemblance to the oppressive environment at home but also a medium that enabled elite women's mental metamorphosis. Through this process, the palanquin gave Ayako chances to compare herself with her attendants walking on the side and to therefore more deeply sense status differences, but the vehicle also forced her to struggle with the confinement and to reaccept the restrictions attached to her status in such a free and flexible travel environment.

Nonetheless, as in the case of the samurai-merchant status hierarchy, those who accepted their social niche and fulfilled required obligations could receive certain protections from the state. Elite women who accepted their status and the attached restrictions could also enjoy corresponding privileges. Ayako must have more deeply sensed the privileges when she was crossing the Oi River in her palanquin later on her journey. When crossing this notoriously dangerous river, the kind of vehicles the traveler could use was contingent on his or her status and the amount of money afforded. While a samurai might be carried across the river in his palanquin or on a litter with handrails on four sides, a commoner might be carried across on a litter without handrails [2]. As the wife of a magistrate, Ayako was carried across in her palanquin [2]. Nonetheless, witnessing people of lower status crossing the "intimidating" river [2], as she described, without the kind of protection provided by her palanquin, she must have felt grateful for her status privileges. The statusdependent vehicles used for river-crossing were by no means a custom peculiar to this site. One woodblock print in Hiroshige's Fifty-Stations of the Tokaido series depicted travelers fording the Abe River at Fuchu [12]. While the lady in the middle of the painting is carried across in her palanquin, the two ladies next to her, very likely her attendants, are one sitting on a litter without handrails and one being carried on the back of a porter. Coming from the opposite shore are some naked commoner men wading across the river with their horses and cargos. This woodblock print once again vividly shows how status differences in Tokugawa Japan were embodied in vehicles. Witnessing scenes of this kind in their palanquins, elite women like Ayako must have formed a deeper attachment to their upper-class status.

\subsection{Clashes of Different Lifestyles}

In addition to the visual status markers that underlined status differences in a prominent way, witnessing commoner lifestyles was another experience that could help reaffirm elite women's upper-class identity and could thus help consolidate the female hierarchy. For 
example, Ayako sometimes recorded in her diary the life of the industrious commoners: "Peasants kept on plowing the soil, clad in straw rain capes and hats to ward off the rain." She then added, "They are indeed the treasure of the country. Sitting in a palanquin, I, a woman of the samurai class, passed by them as if I had nothing to do with their work. I was ashamed" [2]. The literati woman Tsujo seldom expressed her sentiments in her travel diaries but often recorded her sympathy for poor commoners she met on the road. When she saw farmers working in the field, she exclaimed, "[W] hat a truly difficult thing it is to make a living, and what a terrible thing it is to be guilty of living slothfully off others" [13]. It is clear that, seeing hard-working commoners, these elite women could not help comparing this painful milieu with their own comfortable life. What's more, elite women tended to express their pity not only in their diaries but also through actual assistance. Ayako, upon seeing some poor children selling seaweed at a coastal village, asked her servants to buy a large amount of it [2]. Boto-ni, a widow of a retainer of the Fukuoka daimyo, saw some harlots "solicit[ing] their services" at Shimonoseki [2]. Thinking this was a "wretched scene to witness," as she wrote, she gave them some money, "pretending that she bought them" [2]. Although it is true that these elite women were pathetic and warm-hearted, it should also be noted that, by paying special attention to these poor children and prostitutes and by assisting them, these women were in fact acting as "benevolent patrons." The persona as protective benefactors must also have deepened their identity as elite wives and have deepened the hierarchical differences between them and the prostitutes.

Compared with men, women in the Tokugawa period enjoyed much fewer chances to meet and socialize with people outside their domestic corners. Travel thus offered them the valuable opportunities to recreate and reaffirm their elite identities while comparing their status and lifestyles with others. Elite women's realization and acceptance of this status difference paved the way for the emerging contempt and the ensuing consolidation of the female hierarchy.

\subsection{The Emergence of Contempt}

Tourism not only gave elite women chances to realize and accept their status, but also, in the environment where diversified people converged, shaped elite women's contempt for the non-elites, especially prostitutes. This scornful attitude gave elite women chances to indulge in their higher position in the wife-prostitute hierarchy and also made them into accomplices in dividing women into two categories.

Elite women's contempt is most apparent in their travel diaries. Although many of them appreciated commoners' hard-working virtue, the elite women sometimes could not help commenting on commoners' inferiority. For example, Ayako described the naked men who carried her across the Oi River as "scary [and] coarse-looking" [2]. Oda Ieko, wife of a wealthy merchant, also described the women she saw in a poor village as having "unkempt" hair and wearing clothes that were "so shabby" that she could not tell "whether it was a man or a woman." When it comes to prostitutes, the depraved stereotype and image of prostitutes shaped by men and the erotic print culture seemed to have taken root in women's minds - the elite women would sometimes naturally treat prostitutes as another kind of women (or non-humans) and would even express contempt for the harlots, whom they saw to fall into the lower rank in the female hierarchy. For example, Towako, the wife of a samurai family, would specifically record in her travel diary the number of prostitutes she saw at inns [2]. She would also comment on unsophisticated prostitutes' poor manners in her diary, although sometimes when meeting with congenial harlots she would happily chat with them [2]. Her habit of recording the number of prostitutes as if they were local specialties and her fickle attitude towards prostitutes are evidence for her perception that prostitutes belonged to another category of human beings that entailed special observation. This mentality might have in turn shaped her understanding of the female hierarchy. In many cases, curious female travelers would also intentionally go to take a look at the prostitutes at famous brothels, seeing the whores as local landmarks in a similar way male travelers saw prostitutes as a connection with the locals [5]. For example, when staying at a post town famous for its brothels, Nishimiya Hide, the daughter of a samurai family, went to observe the local prostitutes and described her experience as "most enjoyable" [5] Although this remark may not be derogatory, it is sure that she was treating these prostitutes as another category of human beings, or another kind of women in the female hierarchy.

Travel sometimes could also unconsciously reflect elite women, or in this case, a former elite women's contempt for prostitutes. Takejo was born into a samurai family but became an entertainer (shirabyoshi). Since the Tokugawa shogunate only strictly restricted the mobility of women with socioeconomic values and status, [5] her new identity freed her from almost all sorts of travel regulations. As a result, when going through the Hakone barrier on her journey from Nagoya to Edo in 1720, she was allowed to pass immediately because, as she said, "it has been established that the likes of prostitutes and itinerant entertainers are people apart." She then wrote, "Should I be glad? Should I be saddened? I cannot say" [5]. It is evident that she felt ambivalent when the barrier made her realize her newly acquired freedom but also her relegated status similar to that of women of the prostitute rank, who were discarded by society. Takejo's complaints and indirect scorn for prostitutes can prove how the inferior image of prostitutes had taken roots in elite women's minds. Takejo and Towako's contempt thus 
also show how travel shaped and reflected elite women's condescending attitude towards prostitutes and how this attitude could have consolidated the female hierarchy.

As a result, the malleable elements on the roaddifferent vehicles, clashes of diverse lifestyles, as well as the environment that allowed elite women to, though sometimes unconsciously, express their contempt for poor prostitutes-gave elite women opportunities to realize and accept the elite status and then the female hierarchy favored by men. Although unconsciously, tourism reinforced elite women's hatred against those poor prostitutes, and these elite women as a result became accomplices in reinforcing the dichotomy between "wives" and "prostitutes." This female hierarchy then gave men excuses for marrying virtuous wives but at the same time seeking extramarital affairs with prostitutes. In other words, the dichotomy furthered by elite wives' contempt for prostitutes can be seen as an internal division amongst women that could, and would, be well employed by erotic men who hoped to divide and rule women.

\section{CONCLUSION}

In such a prosperous floating world of the Tokugawa period, travel by no means provided men and women certain autonomy to recreate their ideology and identities. Sometimes these recreations were beneficial, especially for women, in that travel allowed them to enlarge their social circles and broaden their horizons [2]. But crossing the demarcations could also bring negative results. It was in such a flexible environment that the wife-prostitute female hierarchy was reinforced by both erotic men and contemptuous women. While the Tokugawa shogunate might be blamed for unintentionally initiating the trend, travel took a significant role in giving men chances to form an attachment to prostitutes and in giving elite women a diverse environment to reaffirm their social status and to generate hatred for prostitutes. Transformations on both men and women's part then contributed to the consolidation of the dichotomy between wives and prostitutes in early modern Japan. More importantly, this consolidation paved the way for further development of the male-oriented Japanese society all the way to today, in which Japanese women have long been exploited by the dichotomy, or the sexual double standards, as modern sociologists would say. In the Meiji era that followed the Tokugawa period, the double standards might be best exemplified by the Freedom and People's Rights Movement activist Emori Ueki's behavior of having sex with prostitutes on the one hand but aspiring to marry a knowledgeable and virtuous wife on the other. From his point of view, this idea was by no means immoral or at odds with his support for gender equality. As the Japanese sociologist Shizuko Ueno explains, Ueki saw prostitutes as belonging to a different race that did not deserve equality [14].

\section{REFERENCES}

[1] McClain, J. (2002) Japan: A Modern History. W.W. Norton \& Company, Inc. New York.

[2] Shiba, K. (2012) Literary Creations on the Road: Women's Travel Diaries in Early Modern Japan. Translated by Motoko Ezaki. University Press of America. Lanham.

[3] Sommer, M. (2012) Forward to Amy Stanley Selling Women: Prostitution, Markets, and the Household in Early Modern Japan. University of California Press. Berkeley and Los Angeles.

[4] Stanley, A. (2012) Selling Women: Prostitution, Markets, and the Household in Early Modern Japan. University of California Press. Berkeley and Los Angeles.

[5] Nenzi, L. (2008) Excursions in Identity: Travel and the Intersection of Place, Gender, and Status in Edo Japan. University of Hawaii Press. Hawaii.

[6] Edited by Wm. Theodore de Bary (2011) Finding Wisdom in East Asian Classics. Columbia University Press. New York.

[7] Kamei-Dyche, A. (2011) The History of Books and Print Culture in Japan: The State of the Discipline. Book History, 14: 270-304.

[8] Screech, T. (2009) Sex and the Floating World: Erotic Images in Japan, 1700-1820. Reaktion Books. London.

[9] Jippensha, I. (2011) Shank's Mare. Translated by Thomas Satchell. Tuttle Publishing.

[10] Ando, Hiroshige. Goyu, Tabibito Ryujo. https://www.metmuseum.org/art/collection/search/5 5558.

[11] Ihara, S. (1963) The Life of an Amorous Woman: And Other Writings. Translated by Ivan Morris. New Directions.

[12] Ando, Hiroshige. Travellers Fording the Abe River at Fuchu.

https://www.metmuseum.org/art/collection/search/3 6941.

[13] Keene, D. (1999) Travelers of a Hundred Ages. Columbia University Press. New York.

[14] Ueno, Shizuko. (2015) Onna Girai: Nippon no Misogyny. Translated by Lan Wang. Sanlian Book Store. Shanghai. 